\title{
Why you and not me? Expressions of envy in Sweden and Indonesia
}

\author{
Adrianson, Lillemor \\ Boras University, Sweden (lillemor.adrianson@hb.se) \\ Ramdhani, Neila \\ Gadjah Mada University, Indonesia (neila.ramdhani@ugm.id)
}

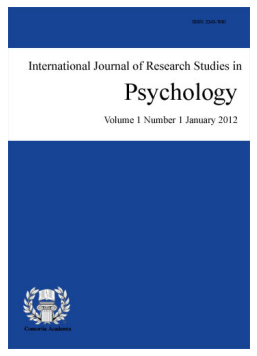

ISSN: 2243-7681 Online ISSN: $2243-769 \mathrm{X}$

Received: 2 March 2014

Revised: 19 March 2014 DOI: $10.5861 /$ ijrsp. 2014.743

Accepted: 20 March 2014

OPEN ACCESS

\section{Abstract}

The purpose of the present study was to describe experience of envy in two different cultures, Indonesia and Sweden. Envy is a feeling that most people have experienced and mostly regards as shameful. The concept relates to a variety of feeling that shows its complexity. The result shows that envy had a wider meaning in the Indonesian language than in Swedish, and consisted of emotional words that were rare among the Swedish respondents. The Swedish respondents' descriptions were, with few exceptions, connected to a malicious (ill will) meaning while it was obvious that the Javanese respondents used also the concept of benign envy (without ill will). Jealousy and envy seemed to overlap each other more in Bahasa Indonesia than in the Swedish use of the words. The latter had a distinct word for schadenfreude that was lacking in Bahasa Indonesia. For the Swedish respondents, wanting to have what another person possesses was a central element of envy, for example prosperity or competence. The Javanese respondents stressed relationships, achievements and personal characteristics' as main causes for envy. Both the Swedish and Javanese respondents reported that a person who they knew and with whom they had an established relationship, such as a friend or a fellow student, had envied them and the causes for this were about the same as their own.

Keywords: emotion; culture; malicious; envious; Javanese 


\section{Why you and not me? Expressions of envy in Sweden and Indonesia}

\section{Introduction}

The two descriptive studies presented in this article examine the emotions and cognition of envy in two respondents groups, one from Sweden and one from Java in Indonesia. The concept of envy has been of interest for a long time. It is seen as a universal human emotion (Callaghan et al., 2007), but also one of the most shameful to harbour against another person. Smith and Kim (2007) reviewed the words of the Christian philosopher Aquaro '... for envy being the core emotion driving most sinful behaviours and thus creating the need for the 10 commandments to combat these sins' (p. 46). According to Islam, 'hasad' is a disease of the heart and creates impurity (Aziz, 2006). Buddha said that the root of all evil and suffering in life was desire, and maybe envy is the source from which all other sins breed. Dante (1803) had a place in Hell for the envious, whose 'eye-lids were sewn up with wire since they could not bear to look at the joy of other humans' (verse XVI, p. 175). Weyl (1984) argued, in modern time, that the Jews were deeply envied in Europe before the Nazi holocaust started. Children learn the concept early, both in Sunday school (e.g., from the Bible, Cain and Abel; Josef and his brothers) and in fairy-tells (Cinderella and her envious sisters).

Envy has its roots in a wish to be superior (Alberoni, 1993), and we constantly compare ourselves with the people close to us who are our equals. If the comparison is to our disadvantage, we feel humiliated, worthless and inferior (Parrott \& Smith, 1993). Unlike many other emotions, the experience of envy does not give rise to a unique affective state or facial expression (Sabini \& Silver, 2005). It is a complex mix of unpleasant psychological states as discontent, longing, ill will, wistfulness, self-criticism, dissatisfaction, and self-awareness (Smith, Kim, \& Parrott, 1988). These feelings of inferiority, injustice and resentment are best to conceal from others because it is such an ugly feeling to harbour. We need to feel in balance and keep some sense of equilibrium in order not to experience emotional dissonance. One way of coping with the negative feelings is to neglect them and try to find other areas to rebuild our feelings of self-evaluation. Another way is to belittle the envied person that we have compared ourselves with - our ideal. Alberoni compare this with a survival instinct, to facilitate successful social competition and Schoeck (1969) argued that envy is a social impulse and needed to hold the members of society in equilibrium vis-à-vis each other. Envy is one of the most socially repulsive emotions, and can be devastating for both groups and the individual in organisational outcomes, for example in situations where malicious gossip allows flowing (Wert \& Salovey, 2004). There is a distinction from the meaning of 'ambition' since it is not an effort to show off any ability or skill, but an innate wish to diminish the more gifted. In doing so, we are trying to protect our inner self.

Envy is an interesting concept from many points of view, and results from research studies show its importance in group processes (Duffy \& Shaw, 2000), on different educational levels (Martin, 1996; Massé \& Gagné, 2002), and in the workplace (Dogan \& Veccio, 2001; Fischer, Kastenmüller, Frey, \& Peus, 2009; Korvela, 2008). According to Heelas (as cited in Patient, Lawrence, \& Maitlis, 2003) the concept of emotions as cultural elements got support by cross-cultural research that has documented the cultural specificity of many emotions, their meanings in social life, and their public display. In this descriptive work we aim to review the basic components of envy, and to study the variations in the associative meaning of the word 'envy' as well as situations including the envious and the envied in two very different cultures.

\section{Related literature}

\subsection{Definitions and Descriptions}

Envy is frustrated desire turned destructive (Schoeck, 1969). In the film 'Amadeus', Salieri sets out to 
Why you and not me? Expressions of envy in Sweden and Indonesia

destroy Mozart as a person for effortlessly writing the glorious kind of music that Salieri was able to recognise, but could not produce himself. In envy, the urge to reach out becomes the urge to destroy (Grow, 1996). There seems to be some consensus that the definitions of envy emphasise that it is 'an unpleasant, often painful emotion characterised by feelings of inferiority, hostility, and resentment produced by an awareness of another person or group of persons who enjoy a desired possession, object, social position, attribute, or quality of being' (Smith \& Kim, 2007, p. 47). When Salieri compared himself with Mozart and realized that he never would be able to produce anything close to Mozart's music, the comparison was devastating for him. He knew that Mozart was superior and this raised his feelings of inferiority, and envy. The example of Salieri also shows the hostility that follows with envy, a discontent so deep that he was able to destroy his enemy. Ill will is an important quality of envy and this is a deeper emotion than merely begrudge (Maijala, Munnukka, \& Nikkonen, 2000; Miceli \& Castelfranchi, 2007; Parrot \& Smith, 1993; Smith \& Kim, 2007). It distinguishes from resentment and sense of injustice, which often is considered as a part of envy. Ill will has a component that is characterised by the envier's inherent wish that the envied suffer harm. Epstein (2003) described ill will of envy like 'malice that cannot speak its name, cold-blooded but secret hostility, impotent desire, hidden rancour and spite, all cluster at the centre of envy'. The ill will that the envious person is showing is coming from frustration (Smith, Parrott, Diener, Hoyle, \& Kim, 1999), knowing that the desired attribute (object, position, etc.) is out of reach. From this point of view, the deepest feelings of pure envy cannot be a good feeling.

Non-malicious envy (benign) is free from ill will, or of hostile meaning, and is closer to admiration than to envy (Foster, 1972; Smith \& Kim, 2007; Van de Ven, Zeelenberg, \& Pieters, 2010). Evolutionary theories (see Hill \& Buss, 2008; Ratner, 2000) consider envy a motivator to be better off than others and ensure own resources for competitiveness. Aristotle who, in The Rhetoric, wrote of good envy as envy ending in admiration, also pointed out that envy is pain at the good fortune of others' (Aristotle, Rhetoric, Bk II, and Chapter 10). Ashwin (2004) wrote that, 'initially, before the sadness at another's joy, before the need to spoil, the first glimmer of apprehension is the recognition of something good. That acknowledgement may be painful and instantly contaminated by wanting it for oneself, hating it, or needing to spoil it, but the nascent energy is discrimination; sifting, sorting all the stimuli that enter the awareness and knowing this is good and, therefore, desirable' (p.13). To continue with the Salieri example one can say that the difference between 'admiring envy' (benign) and 'malicious envy' could be that in the first case, Salieri would have submitted to Mozart's superiority and felt resignation and inferiority, while in the second case, the destructive wishes (ill will) are prominent. Another way to deal with feelings toward someone that is admired is to be inspired and work harder (Van de Ven, Zeelenberg, \& Pieters, 2011) and try to be elevated by the other person and improve themselves (Schnall, Roper, \& Fessler, 2010).

Resentment is often triggered by a social comparison with someone, or a group of persons, having an advantage that we do not have. If we feel that the envied party does not deserve the advantage given to him/her/them, feelings of injustice occur (Smith \& Kim, 2007). Anger is a component in both malicious envy and resentment but in the latter, it follows of feelings of justification. It is the sense of undeserved superiority that creates the hostile attitude (Smith et al., 1988).

\subsection{Episodic and Dispositional Envy}

Whether envy should be seen as episodic (temporary, situation-specific) as suggested by Cohen-Charash (2009) or dispositional (stable tendency) as suggested by Smith (2008) is discussed among researchers (see Cohen-Charash \& Mueller, 2009). The main question is whether envy has one component (Smith) or two components (Cohen-Charash). Most people do experience envy but according to Cohen-Charash, some individuals have a higher tendency to experience envy than others do. The chronically envious individual differs from the individuals who only sometimes feel envy in some contexts. Smith et al., (1999) argued that an envious personality is characterised of a chronic sense of inferiority, and a chronic feeling of ill will toward those who are better off while Cohen-Charash believed that a person need not be chronically malicious or feel inferior to experience episodic envy. 
Episodic envy is regardless of a person's general level of inferiority or ill will and is limited to a particular experience. The numbers of people that experience episodic envy are greater than the number of people who are predisposed to episodic envy. This means that it is more widespread and profound than a personality trait. The consequence can be a dishonest attitude (Gino \& Pierce, 2009) and cause situations where a person is able to perform unethical acts because other people are doing it (Cohen-Charash). Episodic envy is described as a form of envy that involves not only a desire to have what someone else has, but also to harbour ill will against others and attempt to destroy the annoying object. Envy is composed of a feeling component and a comparison component. The feeling component correlates with negative emotional reactions and behavioural reactions while the comparison component correlates with behaviours intended to improve one's position. The conclusion from Cohen-Charash is that episodic envy predicts reactions to envy beyond dispositional envy. Hill, DePriore, and Vaughan (2011) supported this finding in a series of experiments showing that envy had both an affective component and a cognitive processing.

\subsection{The Difference between Envy, Jealousy, and Schadenfreude}

In the general case, envy involves two people and jealousy involves three people (Alberoni, 2003), the latter more often used for romantic jealousy. In general, people find it easier to admit to jealousy than to envy (Alberoni, 2003; Kast, 2002). Envy is an expression for a desire for something that someone else is in possession of, while jealousy is more about losing a relation with a person to a rival. Tellenbach (1974) expressed this as 'jealousy is not a wanting-to-have but rather a wanting-to-hold' (p. 464). Envy connects to words like discontent, desire, longing, and ill will, and jealousy to words like fear, anger, and suspicion. Smith and Kim (2007) named this a semantic confusion, since people often use the terms envy and jealousy interchangeably, but the overlapping usage is asymmetric. The study of Smith et al., (1988) compared situations where participants wrote short descriptions of situations in which they felt either strong envy, or strong (romantic) jealousy and found that envy corresponded to the standard definition of envy in almost all cases, while jealousy evoked envy and jealousy descriptions to the same degree. The authors' conclusion was that the linguistic ambiguity leads to a false sense that envy and jealousy are comparable emotions.

Parrott and Smith (1993) found that feelings of inferiority, longing, and resentment were relatively more salient in envy, and feelings of distrust, anger, and fear of loss were more characteristic of jealousy. This study was replicated by Haslam and Bornstein (1996) who reported that the distinctive features of the two emotions compose discrete, bounded categories that correspond closely to traditional definitions, envy is characterised by feelings of shame, failure, dissatisfaction with self, and longing for what another had, whereas jealousy is characterised by feelings of betrayal, distrust, rejection, threat and loneliness. Envy and jealousy appear to be complex affections that are distinct but often combined elements of the emotional repertoire. For some languages (i.e., Swedish) there is a clear distinction between being envious and jealous, that is in accordance with the studies of Parrott and Smith and Haslam and Bornstein. In addition, as Parrott and Smith pointed out, jealousy and envy can co-occur, for example to be jealous of an unfaithful partner and envy the concurrent.

When a misfortune befalls another person, we can experience schadenfreude; an emotional reaction defined as taking pure pleasure in another person's misfortune. The empirical support for this reaction shows that schadenfreude specially stir up when an envied person experiences a misfortune (Feather \& Nairn, 2005). There is as strong relation between envy and schadenfreude, as it is between envy and ill will. People that harbour schadenfreude do it whether it is deserved (Brigham, Kelso, Jackson, \& Smith, 1997) or undeserved (Smith, Turner, Leach, Garonzik, Urch-Druskat, \& Weston, 1996) for the envied part. It is a component in envy showing the underlying feelings of hostility. In this sense, envy cannot have positive characteristics, and if it has, it is not envy. Miceli and Castelfranchi (2007) express this as 'in our view .... true envy may arise, provided that one's longing for the good is complemented by other ingredients, such as .... one's unfavourable comparison with, and one's ill will against the other' (p. 451).

Schadenfreude may not be condemned as strongly as envious hostility but it is not a social acceptable 
emotion either. van Dijk, Ouwerkerk, Goslinga, Nieweg, and Gallucci (2006) found that envy predicted schadenfreude beyond hostile feelings, indicating that the conflicting results of earlier studies cannot depend of the use of hostile feelings in the assessment of envy. Both envy and hostile feelings had their own individual contribution to the experience of schadenfreude. They also showed that envy predicted schadenfreude when participants learned about a misfortune of a same gender target, whereas envy did not predict schadenfreude when participants learned about a misfortune of a different gender target. These results indicate that envy predicts Schadenfreude when there is a similarity between the target of schadenfreude and the envying person. In a recent work, van Dijk, Ouwerkerk, Wesseling, and van Konigsbruggen (2011) demonstrated that people had stronger feelings of schadenfreude when they experience a threat to the individual self and to a positive self-view, which supported their earlier results.

Quintanilla and Jensen de Lo'pez (2013) argued that absence of the concept of Schadenfreude in some languages is a notion that the concept is not an additional emotion to envy but can follow feelings of envy. However, they do recognise that people living in countries that have the concept as a lexical expression (e.g., Germany, the Nordic countries) can experience it as a feeling that is different from envy. The feeling of schadenfreude is a feeling of happiness while envy is a feeling of glum and depression. To be happy when people 'get what they deserve' is not necessarily including ill will or even resentment.

Feather and Sherman (2002), Hareli and Weiner (2002) and Leach and Spears (2008) failed to find a relation between envy and schadenfreude. Other researchers found a positive relation between the two concepts (e.g., Brigham et al. 1997; van Dijk et al., 2006). Feather and Sherman suggested that resentment about another's undeserved success rather than envy that predicted schadenfreude. The studies of envy and deservingness in relation to schadenfreude (Feather, 2012; Feather, McKee, \& Bekker, 2011; Feather, Wenzel, \& McKee, 2013) reported that when someone is to blame him- or herself for a misfortune, schadenfreude could be more pleasant than when the misfortune is not deserved as a result of the individual's cognitive appraisal.

Feather et al., $(2011,2013)$ found that deservingness played a major role in relation to other emotions and developed a model with studies on schadenfreude linked to global self-esteem, pain of inferiority, hostile and benign envy, resentment, perceived deservingness, and sympathy. They found that deservingness emerged as important in combination with the other variables and that they formed a complex structure of relations linking to schadenfreude. The results indicated a solution to the earlier conflicting results to the relation between envy and schadenfreude. Feather et al. explained that the disagreements maybe is a result of not being able to differentiate between benign envy and hostile envy. They suggested that hostile envy is a blend of resentment and anger, and benign envy is a blend of admiration and wanting to be like the envied person. These two forms of envy should be considered along with resentment as emotions resulting in expressions of schadenfreude. Feather (2012) has written an overview of 20 years of research on the topic, from 'tall poppies' to a model to a conceptual analysis of deservingness and has focused on schadenfreude during the last years.

\subsection{Envy as a Process}

Spielman (1971) differentiated between four affect states; a wish to equal or imitate the envied subject, and second, a sense of lacking something or to feel inferior, inadequate that can result in a lowered self-esteem. The third state is a longing for the desired possession, and last, a feeling of anger, discontent, resentment or ill will. This is a more severe way to destroy the envied object. Alberoni (1993) also describes different stages in the process of envy development; the first appear when we realise that someone is superior to us in something that we value (e.g., intelligence, musicality). Whenever we see the subject for our envious feelings, we are reminded of our own inferior position. We want the person or situation that is causing uncomfortable feelings to disappear, and one strategy to do this is to deny the value for our envied object (e.g., our subject is not intelligent at all). Denial is not very effective and the strategy of value revision is needed (e.g., use other criteria for intelligence). This will probably not work and the third strategy is to use projection of lesser value (e.g., other pitiful qualities). The suspicion that we are envious is so contemptuous that we have to draw back not to feel too ashamed of 
ourselves. Ill will feeds on the shame and the result can be harassments, for example to set off rumours (Wert \& Saloway, 2004) that can cause problems and ruin a carrier or a reputation.

Festinger identified this process in 1954 when he considered social comparison as a basic human drive with the main function to precise self-evaluation. Included in these social comparisons are also comparisons of personal attributes, abilities, social positions, possessions and achievements. An important part in Festinger's theory is 'the comparative other'. In social situations, people evaluate themselves according to their relative position only by comparison to others (Crusius \& Mussweiler, 2011). This results in an upward motivation, to get a positive result in the comparison, to be more intelligent, more beautiful, get better results, or have better relations with management. It is obvious that not everybody can be a little bit 'more' than others; therefore the comparison itself results in a competition. Relative deprivation theory (Crosby, 1976) claimed that resentment, anger and other deprivation-related emotions of the same kind vary with the subjective assessment of one's status. Crosby's model showed that an individual feels resentment about failure to possess something (X) only when he sees that similar others possess $\mathrm{X}$, he wants $\mathrm{X}$, and he feels entitled to possess $\mathrm{X}$, as explained by Crosby.

The process in work here is comparison. If someone is outperforming the self in an area of less importance, it will create a reflection process and the closer the relationship the greater enhancement to self-evaluation. Cohen-Charash and Mueller (2007) also stated that the importance of the area to the envious person is crucial. It means that the envious person is in no need to feel generally inferior. It is enough with a single comparison that is in disadvantage for the envious person to start to activate the sequence of thoughts that will end up in envy. Some evidence (Nosanchuk \& Erikson, 1985) actually suggests that while choosing objectively superior principles for comparison, people see themselves as similar (not inferior) to them. This is a way for the envious individual to confirm his/hers enhanced view of him/her, rather than actually enhance it. Envy arises from an upward social comparison and it can be less prominent if it is possible to make the differences to the other person smaller. This can be achieved by moving oneself up to the level of the other, and by pulling the other down to one's own position.

Van de Ven, Zeelenberg, and Pieters (2009) discussed the distinction between benign and malicious envy and conclude that the experience of benign envy leads to a moving-up motivation aimed at improving one's own position, whereas the experience of malicious envy leads to a pulling-down motivation aimed at damaging the position of the superior other. They also discuss how non-hostile envy motivates people to improve themselves but only if the situation is possible to change. If it is unchangeable, envy can lead to admiration instead of being forces to self-improvements. In a recent study (2012) they found that benign envy was experienced more when the situation was deserved, and the most when the situation was appraised as both deserved and controllable. Fischer et al. (2009) also believed that comparison down helps the individual to overcome negative emotions, while the benchmark upwards instead causes threat to the ego and thus contribute to the experience of envy. People regularly compare themselves with others to appraise their relative status amongst their likes but maybe the substance of envy has been confounded with its consequences as Tai, Narayanan, and McAllister (2012) suggested. They see envy as pain at another's good fortune and this view allows for both positive and negative consequences.

\subsection{The Envious and the Envied}

Just as we envy others who are similar to us (see e.g., Parrott, 1991; Salovey \& Rodin, 1984; Smith \& Kim, 2007) we also are envied by similar others. It is common (at least in Western cultures) to be proud when other people are envious. It is a sign of success and social recognition (Rodriguez Mosquera, Parrott, \& Hurtado de Mendoza (2010). The object of envy can be almost anything of importance to the envious individual, materialistic values and talents, abilities of all kind, social positions or psychological aspects. In general, people are more envious of privileges (Kast, 2002), positions and status, and income. According to Veccio (2005), others envy was experienced as less negative than having envious feelings toward other people. Rodriguez Mosquera et al. (2010) confirmed this view in two studies that indicated that being envied had a positive 
outcome, e. g., increased self-confidence but also a negative outcome, e.g., fear of ill will from others. They also found that being envied had more positive and more negative psychological and relational consequences among achievement oriented persons (like Swedish) than among those who were oriented to cooperation and interpersonal harmony (like Indonesians).

Miceli and Castelfranchi (2007) stressed that it is important for the envious individual not only to possess sufficient resources and skills but also that others believe that it is that way. An experiment by Salovey and Rodin (1984) showed the importance of both similarity and self-relevance in envy. Their participants received feedback on a career aptitude test that stated that their career prospects in a field of their interest were either outstanding or poor. After reading the statement, they were provided with career prospects of another student who had done better or worse than they had on either the same career field or a different, less self-relevant career field. Envy occurred only when participants, having received negative feedback, compared themselves with the student who had done better on a career domain relevant to them.

Hostile envy includes feelings that are harmful for an individual's self-esteem. In connection with other negative feelings, it can even be damaging for the envious and for the envied. Ill will and schadenfreude are two expressions that the serious envious person will likely display. The emotion is so strong that the envious person is willing to give up own advantages as long as it means that the other person will have a disadvantage.

\subsection{Cross-Cultural Aspects on Envy}

The concept of the seven cardinal sins is a product of the ancient Greeks and is of importance in the understanding of the bases of both Christian and Islamic cultures. Both religions are clear in their condemnation of envy. The Bible refers to envy as 'the rottenness of the bones' (Proverb 14:30). Moreover, envy when compared to envy and wrath is so terrible that the question 'who is able to stand before envy is raised?' (Proverb 27:4). In Islam, Hasad (destructive jealousy) is among the most destructive feelings someone can harbour towards the next person. It causes him to wish evil for others and to be happy when misfortune befalls them. The word 'hasad' is also including the wish that the good thing is taken away from the other person and given to the envious person instead.

On the other hand, Islam encourage Ghibtah (envy that is free from malice), which means neither loving the loss of the blessing nor hating for it to remain with the person, but desiring the same for oneself without the removal of the blessing from others (Aziz, 2006). Christianity does not have the similar distinction in the conception of envy. Envy is a compounded, universal emotion (Smith \& Kim, 2007) that is learned, not genetically based (Hupka, Otto, Tarabrina, \& Reidl, 1993). Ratner (2000) posited that the cultural characteristics, development, and functions of psychological phenomena are shaped by social activities and cultural concepts. Integrated into cognition, emotions are cultural, just as thinking is, 'emotions are feelings that accompany thinking' (page 6). Smith et al. (1999) emphasised that most cultures have a word meaning envy, even though words for other common social phenomena may be absent, and that most individuals seem capable of feeling it. Although envy is an emotion, found in most cultures and felt by most people, there are important individual differences in the inclination to feel it. Empirical work of Smith and his colleagues $(1988,1994,1996)$ also showed that both inferiority and ill will are found in autobiographical accounts of envy in everyday life.

Fontaine, Poortinga, Setiadi, and Markham (2002) stressed that it is necessary to distinguish between three cognitive representations in order to understand cross-cultural variations; emotion terms (linguistic), representation of facets of emotion processes and states in terms of cognitive similarities and differences between emotion terms (representational), and emotion processes and states themselves (internal). Fontaine et al. noted that the mere fact that two terms are translation-equivalent is not evidence enough of their cognitive correspondence. It is not necessary to have a word for a certain emotion for it to be experienced (Breugelmans \& Poortinga, 2006; Van den Ven et. al, 2009).

Hupka, Lenton, and Hutchison (1999) estimated that about $20 \%$ of the world's languages make no 
difference between envy and jealousy insofar as they have only one word to represent the two concepts. Hupka et al. (1993) found that when their subjects were instructed to rate the extent to which they associated given nouns (by experimenter) with envy and jealousy, the association overlapping was $68 \%$ in U.S. $28 \%$ in Germany and $12 \%$ in Russia. In all three countries, money, prestige, property, revenge, selfishness, status, and wealth, were associated with envy (p. 189). Kim and Hupka (2002) performed a study in United States and Korea to explore similarities and differences in free words associations in meaning of words, among them the concept of envy. They found, against their hypothesis that the associative meaning of the two concepts overlapped to the same extent in America and Korea, despite the fact that the latter has lexical definitions that clearly distinguish between the two terms. The Americans associated (the five first words) envy with jealousy, hatred; wanting, greed, and anger while the Korean associate envy with jealousy, hatred, girls, fight, and greed (p. 239). In total, there were more similarities in word associations between the two cultures than there were differences. The authors stressed that the results are opposite to the view that emotion terms are specific for cultures and for languages and suggested that major structural components of emotion language maybe is human universals.

The concepts of individualism and collectivism is divided into vertical individualism where individuals are concerned with achievements and horizontal collectivism where they are more concerned of others and avoid putting themselves above others (Triandis \& Gelfand, 1998). According to Rodriquez Mosquera et al. (2010) horizontal collectivism emphasise the positive, emotional reactions to the successes and achievement of others. Their assumption was that people who care about vertical individualism should feel pleasure about being envied by others, while people who are oriented towards horizontal collectivism should feel less pleasure about being envied by others because of the collectivism's emphasis on cooperation and social harmony. Their results confirmed that the European Americans and the Spanish differed in their value orientations where the European Americans valued achievement more than the Spanish did. The Spanish respondents valued cooperation and connectedness in social relationships more than the European Americans did. They, on the other hand, enjoyed having something someone else wanted more than the Spanish did, especially when what they had was so precious that it would make the fellow student feel inferior to them. Under these circumstances they expected begrudge and ill will more than the Spaniards did. Whereas the European Americans expected envy from the fellow student, the Spanish expected the fellow student to feel happy for them for winning the internship or having the life they had. The Spanish focus on cooperation and connectedness expected a more benign form of envy from the fellow student than were seen in the European American student group. However, there can be considerable within-country variation, to name a culture only as individualistic or collectivistic can lead to overgeneralisations (Oyserman, Coon, \& Kemmelmeier, 2002), and this is particularly the true for Asian cultures. Chang (cited in Chang, 1997) argued that by describing cultures (i.e. Chinese) as only collectivistic is to focus on the structure and ignore much of the individual aspects in Asian cultures.

\subsection{The Present Descriptive Studies}

In Scandinavia, there is a concept called the 'Law of Jante' that consists of ten rules that refers to a shared, mental perception of other people. The individual trying to stand out in any way has to be discouraged and told that they are not better than anybody else, often expressed as 'who do you think you are?' It is similar to the 'tall poppy syndrome, meaning that someone who accomplished positive is not recognised because people do not think that the individual is worth it. The creator of this law was a Danish-Norwegian author, Aksel Sandemose (1933/1936), who wrote a novel about a small Danish town (Jante) where individual success and achievement were looked upon as unworthy and inappropriate. The rules express the same underlying thinking: Do not think that you are better than we are:

$>\quad$ You're not to think you are anything special.

$>\quad$ You're not to think you are as good as we are.

$>\quad$ You're not to think you are smarter than we are. 
$>\quad$ You're not to convince yourself that you are better than we are.

$>\quad$ You're not to think you know more than we do.

$>\quad$ You're not to think you are more important than we are.

$>\quad$ You're not to think you are good at anything.

$>\quad$ You're not to laugh at $u s$.

$>\quad$ You're not to think anyone cares about you.

$>\quad$ You're not to think you can teach $u$ s anything.

In Sweden these rules are often understood as having to do with economic achievement and social hierarchy and are very close to envy, and gossip originate from these perceptions about other people. The social, economic, religious and cultural conditions in Indonesia and Sweden differ quite markedly. Culturally, both nations adhere to harmony among the citizenry. Nonetheless, the reality is very different from that. The social conflict that is rampant in Indonesia today is very disturbing for many parties. Analyses of the cause of the problem are wide-ranging, and suffer from lack of comprehensiveness from the cultural, structural, and individual perspectives. Psychologically, the essence of the problem can be viewed from the standpoint of behaviour, cognition, and emotion. It is the emotion problem, which constitutes the focus of this study. Our research question was to find out if individuals from two different cultures describe, and experience, envy in a similar way.

\section{Method}

The use of free word association in order to study similarities and differences is used by several studies (Hupka et al., 1993; Kim \& Hupka, 2002). In cognitive theory, association models is based on the concepts of nodes and spreading activation (Shiffrin \& Schneider, 1977) and it can be assumed that nodes, such as emotions, is clustered in a semantic network. Since we can assume that the concept of envy is learned at a very early age (Klein, 2003; Quintanilla \& Jensen de Lo'pez, 2013) a specific emotion word will start a spreading activation in the network that is associated with that node.

The questionnaires - We asked the respondents to give free word associations to envy, to describe a situation when they themselves had been envious as well as a situation when they were the target of envy. The subjects were asked to fill in a questionnaire with the following instructions: 'We need examples of what meaning people put in the word envy. This feeling is common for all of us, but it is shown in different ways and with different intensity. Your examples of what you think of as envy is a valuable contribution to the database about the opinion people have about what envy is. We ask of you to answer the questions found below about a) words you associate with envy, b) situations where you have found yourself feeling envious and c) situations where you yourself have been subjected to envy'. Background variables were gender, age, education and occupation, number of siblings (number of brothers and sisters), ethnic belonging and socio-economic group. One question about who the envious or envied person was added in the Indonesian questionnaire. Background variables were gender, age, education and occupation, number of siblings and socio-economic group.

Procedure - In Sweden, we collected data in three ways; an on-line questionnaire linked to different on-going courses in Psychology; an on-line questionnaire published on the Internet, and paper-copies distributed in different courses in Psychology and collected by the teacher. The students were informed about ethical rules and that they could discontinue their participation at any time. In Java, teachers to different courses in Psychology at Gadjah Mada University distributed the questionnaire and informed the students that the participation was voluntary. They filled in the questionnaire at the same occasion and the teacher collected it

The coding principles - As shown above, there is a tendency in American English to blur the use of the 
concept envy and jealousy (see Smith \& Kim, 2007) and the same is relevant for the Indonesian language. Jealousy has too wide a meaning that encompasses romantic envy as well as other relationships. Envy alone, on the other hand, is associated with social relationships, and is thus comparative in nature. The Indonesian Dictionary holds at least three synonyms of the word envy, malicious envy ('dengki'), jealous envy ('íri'), and cynical envy ('sirik'). There is also a word for destructive jealousy ('hasad') related to envy. In the Swedish language there is a more definite meaning of the words; there is one word for envy ('avund'), one for jealousy ('svartsjuka') and one for schadenfreude ('skadegladje') that are not interchangeable. Jealousy is almost exclusively used for the three-part romantic situation.

The concept, and word, of schadenfreude is used in modern Swedish language, and the Swedish proverb 'the joy of schadenfreude is the only true joy', is well known and understood. We discussed these differences beforehand and decided to code each synonym given in accordance with each culture's linguistic meaning. We coded every word the respondent wrote as a synonym of envy, from the first word up to five words in SPSS. Using a frequency table each word with the same content was grouped, for example want to have, greed and craving. The descriptions of situations when envy had occurred were grouped in the same way. We found that this simple grouping resulted in too many groups and, depending on the content, continued to collect groups into categories. An example of this coding is the merging of the group 'money, wealth and economy' and the group of 'things, cars and travels' into the category of 'materialistic aspects',

Respondents - There were, in total, 379 respondents (19\% men and $81 \%$ women) of which 217 were students at different universities and 149 who answered an Internet questionnaire. Thirteen questionnaires had too many answers missing and were excluded. A majority of the respondent, $56 \%$, were between 20-30 years of age, mainly brought up in Sweden (86\%) and had parents who were born in Sweden (70\%). Ten percent of the respondents had no siblings at all, 67\% had 1-2 siblings, 18\% had 3-4 siblings and 5\% had more than 5 siblings. Half of the respondents (50\%) had a high school (Swedish: gymnasium) education and 40\% had 2-4 years of university studies. Most of the students have an occupation within offices and care (medical, elderly, function disturbances, etc.), teachers on different levels in the educational system, service and economy, technology, administration.

\section{Results and Discussion}

Associative words - Twenty-one respondents (6\%) did not give any associative word, 345 respondents gave one word, 221 gave two words, 131 gave three words, 65 gave four words and 36 gave five words. Table 1 shows the first to fifth words and frequencies.

The 10 most often associated words with envy were begrudge, desire, negative emotions, anger, relations, insecure, money, jealousy, dissatisfaction and negative words. In the group of words that were difficult to code (uncoded) were words as 'black', 'looks', 'Cinderella', 'a black cat', 'eyes'. The three most frequent choices for women in the first word group were 'begrudge', 'desire', and 'anger', and for men 'relations', 'begrudge', and 'desire'. The three most frequent words for women in the second word group were 'anger', 'desire', and 'insecure', and for men 'desire', 'relations', and 'dissatisfaction'. The first word given in relation to the total number of associated words, 'begrudged' show 26 associated words, 'anger' 21 words, 'money' and 'jealousy' 14 words, respectively, and 'insecurity' 11 associated words. 'Embittered' was associated with ten words, 'egoism' with nine words, and 'wanting what others have' with eight words. There were no differences (Pearson's' Chi-test) with regard to sex, age, education or social group. Most of the words expressed a mix of negative emotions associated with envy as so many other researchers have pointed out but there were a few positive words as well, e.g., admiration, 'positive carrot'. Thus, the Swedish respondents saw envy as something evil and malicious as suggested by Smith and Kim (2007). Grudging was described as 'pain, bitter, irritation, shame when the person I am envious towards deserves whatever I am envious of'. Embitterment was expressed as 'a wish to be what the other person is or have performed'. 'Careworn, unhappy little people who don't have what they want and therefore can't let other people have it without resenting them'. 
Why you and not me? Expressions of envy in Sweden and Indonesia

Table 1

Associative Words for Envy, Frequencies

\begin{tabular}{|c|c|c|c|c|c|c|c|c|c|c|c|}
\hline \multirow{2}{*}{$\begin{array}{l}\text { Begrudge, embitter, } \\
\text { resentment }\end{array}$} & \multicolumn{2}{|c|}{$\begin{array}{c}1^{\text {st }} \text { word } \\
\text { men } \\
\text { women }\end{array}$} & \multicolumn{2}{|c|}{$\begin{array}{c}2^{\text {nd }} \text { word } \\
\text { men women }\end{array}$} & \multicolumn{2}{|c|}{$\begin{array}{c}3^{\text {rd }} \text { word } \\
\text { men } \\
\text { women }\end{array}$} & \multicolumn{2}{|c|}{$\begin{array}{c}4^{\text {th }} \text { word } \\
\text { men } \\
\text { women }\end{array}$} & \multicolumn{2}{|c|}{$\begin{array}{c}5^{\text {th }} \text { word } \\
\text { men } \\
\text { women }\end{array}$} & \multirow{2}{*}{$\begin{array}{l}\text { sum } \\
111\end{array}$} \\
\hline & 10 & 60 & 1 & 16 & 1 & 14 & 1 & 4 & & 4 & \\
\hline $\begin{array}{l}\text { Desire, greed, craving, } \\
\text { egoism }\end{array}$ & 9 & 34 & 7 & 21 & 2 & 10 & 1 & 4 & 1 & & 89 \\
\hline Negative emotions & 5 & 19 & 5 & 19 & 7 & 17 & 1 & 8 & 1 & 1 & 83 \\
\hline anger, hate, ill will & 8 & 27 & 3 & 22 & 1 & 6 & & 4 & 1 & 5 & 77 \\
\hline Relations, love & 11 & 18 & 6 & 17 & 2 & 11 & 2 & 5 & & 4 & 76 \\
\hline $\begin{array}{l}\text { insecure, low } \\
\text { self-esteem }\end{array}$ & 3 & 24 & 3 & 20 & 3 & 10 & 2 & 3 & & & 68 \\
\hline Economy, money & 2 & 19 & 1 & 7 & 2 & 3 & & 2 & & 1 & 37 \\
\hline jealousy & 2 & 22 & 2 & 6 & & 1 & & & & & 33 \\
\hline Dissatisfaction, frustration & 1 & 7 & 5 & 6 & 2 & 6 & & 1 & & 3 & 31 \\
\hline Negative word (bad, ugly) & 2 & 12 & 1 & 8 & 3 & 3 & & 1 & & 1 & 31 \\
\hline Fear, anxiety, worry & 2 & 5 & & 10 & 2 & 2 & 1 & 3 & & 1 & 26 \\
\hline unfair, injustice & 3 & 6 & 1 & 6 & & 5 & & 3 & & 2 & 26 \\
\hline Positive word & 2 & 5 & 1 & 7 & & 4 & & 4 & & 2 & 25 \\
\hline Uncoded & 6 & 21 & 8 & 12 & & 14 & 2 & 13 & 4 & 5 & 85 \\
\hline Total sex & 66 & 279 & 44 & 177 & 25 & 106 & 10 & 55 & 7 & 29 & \\
\hline Sum & 345 & & 221 & & 131 & & 65 & & 36 & & 798 \\
\hline
\end{tabular}

Situations where respondents were envious - The respondents were asked if they themselves, ever had harboured envious feelings towards someone, and if yes, to describe the situation. Most of the Swedish respondents $(88 \%)$ admitted being envious at some point in their life, while $12 \%$ never had experienced envy towards anyone. 348 respondents described the situation and they were coded into the categories shown in Table 2.

\section{Table 2}

The Cause of Envy, Frequencies and Percentage

\begin{tabular}{|c|c|c|}
\hline Aspects & $n$ & $\%$ \\
\hline Never felt envious on another person & 41 & 12 \\
\hline Materialistic aspects & 61 & 17 \\
\hline General and 'something' & 54 & 15 \\
\hline Social relations & 42 & 12 \\
\hline Others having success in some area important to me & 42 & 12 \\
\hline Family & 27 & 8 \\
\hline Someone is doing what I want to do & 24 & 7 \\
\hline Personal development & 17 & 5 \\
\hline Academic achievements & 16 & 5 \\
\hline Someone having/getting something they do not deserve & 13 & 4 \\
\hline Physical attraction, looks & 11 & 3 \\
\hline & Total & 100 \\
\hline
\end{tabular}

The most often mentioned words in association to envy were those in the category of Materialistic aspects, including money, objects in general, clothes, traveling, homes (i.e., friends traveling abroad and have good economy on top of that). The respondents did not express economic worries or insecurity but a need to own what their friends had, or to be able to travel as often as their friends, to have a house and a vacation house as well, and to have expensive cars, that is, envy of other peoples' prosperity. The second category 'something' was when the respondent could not put an exact word on the feeling, just something that was bothering them in a negative way (i.e. can be happy for another person but also envious and angry and don't want them to have it). The respondents expressed a mix of unpleasant emotions (Smith et al., 1988) and the intensity of the feeling varied 
from intense to a more vague discomfort. 'Social relations' concerned envy on people with more social skills; had more friends; people with an intimate relationship and those who had a close family (i.e. girl who were more popular than I was).

Festinger (1954) argued that it is a basic human drive to compare oneself with others. The respondents in this study often expressed themselves in accordance with the relative deprivation theory (Crosby, 1976) and showed a variety of negative affects depending on how they judged their own status. The category 'Others having success in an area important to me' included situations where other people had accomplished something in a better way than the respondent had, or were more talented within a specific area, or were generally more lucky in life (i.e., when someone else is successful in an area I wish I had succeeded in). This category comprised expressions with an element of competition (Crusius \& Musselweiler, 2011). The respondents felt that they didn't had a specific talent they wanted and felt resentment toward the other party 'Why you and not me?' We are reminded of our own inferior position and shortcomings every time the comparison with the successful, or talented, person is done (Alberoni, 1993; Parrott \& Smith, 1993).

The category 'family' included statements from childhood envy on sibling, (i.e., my younger sister never had to take any responsibility for anything) and also envy with regard to having a family, or even having a happy family, (i.e. I have been envious towards others with a large, well-functioning family and many friends while I have always been alone). Quintanilla and Jensen de López (2013) argued that children as young as three years are able to understand envy and to feel sadness when they want another child's possession. There were some of the answers including childhood poverty and the anger and sadness they felt when they could not afford school outings. The category 'Someone is doing what I want to do' included a variety of situations; experiences, life situations, people being able to get things their way (i.e., a longing to be able to do what someone else is doing).

'Personal development' was described as feelings of failure and not getting anywhere in life (i.e., on those people who have success where I have failure). Some of the respondents wrote that they felt inferior and less worth compared to the beautiful, intelligent, successful and skilled in their workplace. This can be an expression of the character Smith et al. (1999) called chronic envy, to always feel inferior and have feelings of ill will towards people who they feel are superior. There were few respondents that explicitly expressed a wish to destroy others' happiness, or any other negative consequence related to the episodic envy that Cohen-Charash (2009) wrote about, probably because the issue was not addressed in that way. The category 'Academic achievements' included performance in exams and grades but also envy on people having an education (i.e., people with the same education but have high status jobs with better pay and benefits). In one case a person felt mistreated and envied a colleague that had a better education and better treatment. He/She swore to reach to the envied person's level, and also did it. In this case, envy worked as the motivator to improve the respondent's life that Van de Ven et al. (2009) called 'benign envy'.

The category 'Someone having/getting something not deserved' included getting money when the person already was well off, or getting an undeserved favor at work (i.e., when someone is taking credit for something I did). Some respondents had friends that won millions on the lottery, or inherited a fortune, and to get rich without doing anything to earn it was in itself upsetting. One respondent even bought the lot the friend won on, and that was not all positive. They also expressed their resentment when someone was too lucky or too happy compared to them. In these comparisons the respondents saw themselves as similar to the other individual as Nosanchuk and Erikson (1985) pointed out. They also connected 'undeservingness' with injustice (Feather et al (2011, 2013). These situations included, for example, to work hard and wait for your turn without getting any reward or acknowledgment. This could be an expression of episodic envy, not dispositional, since there is no need to be inferior (Cohen-Charash \& Muller, 2009). The few respondents that expressed schadenfreude were in this category. The last category, "Physical attraction' included good looks, people with charisma (i.e. when I meet someone that is better looking than me). There were no differences with regard to sex or age, and situation where the respondents were envious (Pearson's Chi-test). 
Situations where respondents were envied - The respondents were asked if they, themselves, had been subjected to envy from someone else, and again, describe the situation. Someone else had envied most of the Swedish respondents (76\%), while 24\% never had experiences envy from anyone. 336 respondents described the situation and they were coded into the categories seen in Table 3:

Table 3

Reasons for Being Subjected to Envy, Frequencies and Percentage

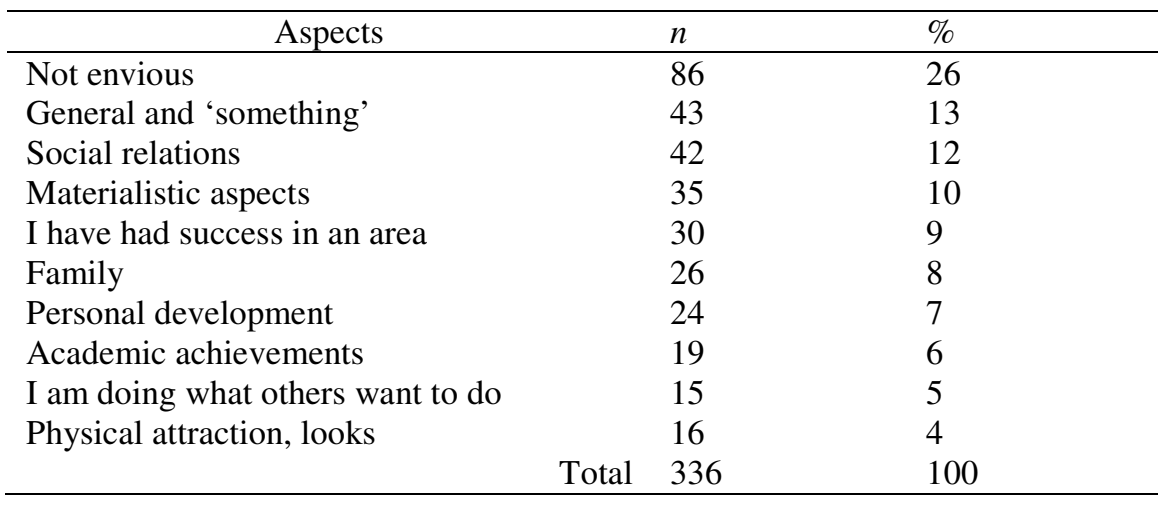

Table 3 shows that the respondents told about people who had shown envy in general, often at workplace or study place. They express this as 'it is hard to be precise"; 'different things'; 'they are indifferent when I succeed and happy when I failure'. The category 'Social relations' were often mentioned for situations where the respondent were popular, had many friends, and had good contacts in work life and alike (i.e. 'I have always been popular in social groups'). 'Material aspects' were mentioned as the third largest category and was mostly about having money; 'a good economy and a stable relation'. The respondents also felt that other people envied them because they have a successful carrier, or have been successful in some other aspect; 'When I have succeeded at work and reached a good position, some people always try to turn me down'.

The category 'Family' was made up of statements concerning envy between siblings but also envy towards the respondent for having a supporting or nice family; 'I have sympathetic and engages parents and some of my friends are envious of that relation'. The category Personal development often had to do with talents that have been developed, or a personality trait; 'Some friends have expressed envy against me because of my ability to get by so many situations'. Envy on Academic achievements mostly concerned grades and ability to comprehend easily compared to classmates. To be able to live the life one wants, to travel and be free and independent were reasons for envy ('I'm doing what others want to do') and physical appearance; 'I am slim and have a sunny disposition which seem to arise envy in some people. I have to struggle with this every day'. There were no differences with regard to sex or age, and situation where the respondents were subjected to envy from someone (Pearson's Chi-test). Table 4 shows a comparison between being envious and being envied.

Table 4 shows that more respondents had been subjected to envy to a higher degree than being envious on someone else. Otherwise, the distributions between the categories are about the same. The main difference is in the category Materialistic aspects where the respondents felt more envy against others than the reverse, which is reasonable, if others had what the respondents not had but wanted. The descriptions of the situations when the respondents were envious of others, or felt others envy toward them, showed the feelings of resentment, embitterment and begrudge that is consistent with the law of Jante.

\subsection{The Indonesian Study}

Respondents - There were 110 Javanese respondents, 29 men (26\%) and 81 (74\%) females, with a mean age of 22 years (range between $18-42$ years, $s=5.22$ ). A majority of the respondents were undergraduate $(70 \%)$ and $30 \%$ had a master degree. Most of the students did not work (75\%) beside their studies. They had between 0 and 11 siblings $(\mathrm{M}=2.8, \mathrm{~s}=1.9)$. They judged their social status as 'fair'. 
Adrianson, L. \& Ramdhani, N.

\section{Table 4}

Being Envious and Being Envied, Percentage

\begin{tabular}{lccc}
\hline \multicolumn{1}{c}{ Aspects } & Being envious & $\%$ & Being envied \\
\hline Not envious/envied & 13 & 26 \\
Social relations & 12 & 12 \\
Family & 8 & 8 \\
Physical attraction, looks & 3 & 4 \\
General and 'something' & 15 & 13 \\
Someone is doing what I want to do & 7 & 5 \\
Personal development & 5 & 7 \\
Academic achievements & 4 & 6 \\
Others having success in some area & 12 & 9 \\
Materialistic aspects & 17 & 10 \\
\hline
\end{tabular}

\subsection{Results and Discussion}

Associative words - The respondents gave 208 associative words to envy. Table 5 shows the categorisation for the words given by the respondents.

\section{Table 5}

Synonym and Meaning of Envy, Frequencies and Percentage

\begin{tabular}{|c|c|c|c|}
\hline Synonym & & $n$ & $\%$ \\
\hline Malicious Envy ('dengki') & & 74 & 29 \\
\hline Jealous Envy ('iri') & & 53 & 21 \\
\hline Cynical Envy ('sirik') & & 47 & 19 \\
\hline Wanting to be different & & 30 & 12 \\
\hline Dislike or hate & & 18 & 7 \\
\hline Cannot bare (to see it happen) & & 3 & 1 \\
\hline Others (uncoded) & & 21 & 10 \\
\hline & Total & 208 & 100 \\
\hline
\end{tabular}

Table 5 shows that the respondents' answers were similar to the meanings in the Indonesian dictionary. They used the three synonyms, that is, malicious envy ('dengki'), jealous envy ('iri'), and cynical envy ('sirik'). Besides that, there were three expressions that is close to the meaning of envy, that is, "wanting something and different from the object reference of envy', 'disliking the envied person because (he/she) has something', and 'feeling not being able to bear to see (something good happen to the envied person)'. The last expression is slightly distinct from the two previous expressions, because 'bear' contains a deeper connotative meaning. Other than these, different words raised and since the meaning of these words was difficult to categorise, they were uncoded. We also found malicious envy ('dengki' or 'ill will') the intention to harm the envied person. Vecchio (2005) explains that envy often surfaces in the context of competition and arises due to feeling of loss or feeling inferior. The effort to overcome these feelings will succeed if the envied person becomes inferior. This 'pulling-down' has as an aim to damage the other person, as Van de Ven et al. (2009) pointed out. According to Williams (2003), envy can force individuals to do something that is harmful to others since envious individuals have moral issues and envy is seen as an 'ugly state of mind' (Aziz, 2006; Parrot \& Smith, 1993).

More than 90 percent of the respondents felt envy towards others, which shows that feeling envious was a common state experienced by the respondents. Almost the same number, $89 \%$, had been the subject of envy. This is divided into four categories that have different interpretations. The first category is the respondents that had felt envious on other people and been the subject of envy. This group can have the tendency of an envious personality, according to Smith (2008) and Cohen-Charash (2009). The second category consists of individuals who had felt envious but had never subjected to envy. The group showed a tendency of inferiority and feeling of not possessing anything to be proud of so there are no reason to be envious at him/her (Vecchio, 2005). The third category is respondents that never had felt envious but had been the subject of envy from other people. They felt 
confident and perceive other people as envious of him/her. The fourth category had never been envious, nor had felt others to envy them. This group showed a tendency to accept the existing reality and seeing what happens to other individuals as something that is bound to happen (Wigley, 2000) It can be related to a religious belief that a higher authority has decided who should have and not have and envy about that decision is a sin.

Reason to feel envious and being envied - The reasons for being envious are seen in Table 6. 'General' included things that were unspecific and related to a holistic comparison. It also included 'something' that was similar to the general category, but the object of envy was not stated. 'Personal development' represented the individuals' achievement and the gain obtained within their personal development. 'Social relations' described the social relation patterns such as being more popular, having many friends etc. 'Family' depicted how the relation was within the family, i.e., warm, affective and harmonious. 'Materialistic' were economic conditions and prosperity, including income and belongings. 'Physical' represented the physical conditions and one's features such as body size, beauty or handsome. 'Fate' connected to the fortune obtained by other individuals and 'love' was romantic relationship between two individuals. Religiosity showed the religious devotion of the individual (as the object of envy). The meaning of 'gender' was not explained.

\section{Table 6}

The Cause of Feeling Envious Toward Others, Number and Percentage

\begin{tabular}{|c|c|c|}
\hline Aspects & Number of responses & Percentage \\
\hline General and something & 48 & 25.4 \\
\hline Personal developments & 45 & 23.8 \\
\hline Academic achievements & 30 & 15.9 \\
\hline Social relations & 21 & 11.1 \\
\hline Family & 10 & 5.3 \\
\hline Materialistic aspects & 10 & 5.3 \\
\hline Physical attractions & 9 & 4.8 \\
\hline Fate & 8 & 4.2 \\
\hline Love & 6 & 3.2 \\
\hline Gender & 1 & 0.5 \\
\hline Religiosity & 1 & 0.5 \\
\hline Total & 189 & 100 \\
\hline
\end{tabular}

'General or something' (Table 6) was the largest category for feeling envious on someone, maybe showing the same vague discomfort as among the Swedish respondents. Personal development became an object and reason of envy, congruent with the assumption made by Hareli and Weiner (2002) which stated that there is a tendency to dislike others' developments and achievements. Feather (1994) also added that individuals who can achieve and develop themselves tend to be disliked if they lack positive social relations and act in a pompous and overconfident way. Academic achievements were a cause for envy among quite many of the respondents and this result was also listed as a main reason in Rodriguez Mosquera et als.' study (2010). Social relation was a source of envy and popularity, possession of many friends became a wanted aspect. The harmony within a family as a source of envy is an expression of between-group comparison concept (Tyler, 1989). When an individual sees a group or another family they tend to experience a fraternal relative deprivation, meaning that the other family has more togetherness, harmony and affection compared to his/her own family (Hogg, Abrams, Otten, \& Hinkle, 2004).

Subject of envy - An individual or a party that was the causes of envy is an important factor when trying to explain how envy rise. Table 7 gives a description of parties being envious and being envied.

It was most common to envy work partners, classmates in college and friends and the same groups subjected the respondents for envious feelings, as well as family members and neighbours. Social comparison tends to be with people similar to us, or in close proximity (Alberoni, 1993; Norman, 2002; Schoeck, 1969). This data seems to be suitable with the characteristics of the respondents who mostly live in the urban areas where the relationship with the neighbours were remote. The proportion of individuals envying and being envied was 
Adrianson, L. \& Ramdhani, N.

similar in percentage. Within the context of social comparison, the object of comparison was usually a person who was relatively close to the respondents. If the object of envy was close the reason for envy could be competitive, otherwise it was sibling rivalry (Wigley, 2000). This founding may implicate a destructive social relation, meaning that the envied party was a close relationship that normally is treated with respect and politeness. The reason for being envied by someone is shown in Table 8 .

Table 7

The Envied and the Envious, Percentage

\begin{tabular}{lcc}
\hline Party & Party envied \% & Party envious \% \\
\hline Working partner or college friends & 50.9 & 41.8 \\
Friends, best friend other than above & 21.8 & 34.5 \\
Family member & 10.0 & 7.3 \\
Neighbours & 0.9 & 1.8 \\
Others & 7.3 & 1.8 \\
Missing & 9.1 & 12.7 \\
\hline
\end{tabular}

Table 8

The Cause of Others Parties Being Envious, Number and Percentage

\begin{tabular}{|c|c|c|}
\hline Aspects & Number of responses & Percentage \\
\hline Personal Development & 37 & 28.5 \\
\hline Academic Achievements & 24 & 18.5 \\
\hline Social Relations & 18 & 13.8 \\
\hline General and 'Something' & 17 & 13.1 \\
\hline Love & 11 & 8.5 \\
\hline Materialistic Aspects & 9 & 6.9 \\
\hline Family & 6 & 4.6 \\
\hline Fate & 5 & 3.8 \\
\hline Physical Attractions & 3 & 2.3 \\
\hline Total & 130 & 100 \\
\hline
\end{tabular}

Personal development was seen as a reason for others to be envious as well as academic achievements and social relations, quite similar to the causes for the respondents' envy of other people. It is reasonable that we have a mutual understanding within a culture and that comparisons between the individuals are about the society's values.

Management of envy - We asked the respondents how they manage envious actions toward them at the time they experienced the event and Table 9 shows the answers.

There were a variety of responses, actions and attitudes mentioned by the respondents (Table 9) and most common was to do nothing specific when someone acted in an envious way. There were positive feelings related to the exposure of envy, for example it could be transformed into motivation for self-development as Fischer et al., (2009), Tai et al., (2012) and Van de Ven et al., suggested (2011). Some actions seemed to be similar to those reported by Rodriguez Mosquera et al., (2010). Their aspect of 'being nice' can be compared to 'engage in a relation', 'ask for advice' and 'giving appreciation' among the Javanese group. 'Being nice' was a European/American (individualistic) strategy more than a Spanish strategy (collectivistic), though. Very few answers reflected a negative attitude.

\subsection{A General Comparisons between the Swedish and Indonesian Study}

A difficulty in cross-cultural studies is the translation of the emotion terms used. Since many of these words have a somewhat different denotation and connotation meaning in different languages, it is not always possible to do more than a superficial comparison in a descriptive study. Table 10 shows the main categories of associated words for the two countries 
Table 9

Attitudes and Actions toward Individuals who Envied, Percentage

\begin{tabular}{lc}
\hline \multicolumn{1}{c}{ Response or Attitudes } & Percentage \\
\hline Nothing specific & 21.6 \\
Become motivated & 13.6 \\
Telling the truth to the person & 11.1 \\
Introspection & 8.6 \\
Act naturally & 8.6 \\
Engage in a relation & 8.6 \\
Ask for advice & 6.2 \\
Giving appreciation & 5.6 \\
Keeping it to ourselves & 4.9 \\
Ignore & 4.9 \\
Compete & 1.2 \\
Dislike & 1.2 \\
Disappointed & 1.2 \\
Avoid & 1.2 \\
Control emotions & 1.2 \\
\hline
\end{tabular}

\section{Table 10}

Comparison of Words Associated to Envy, Language and Categories

\begin{tabular}{ll}
\hline \multicolumn{1}{c}{ Bahasa Indonesia } & \multicolumn{1}{c}{ Swedish } \\
\hline Malicious envy ('dengki') & Begrudge, embitter, resentment \\
Jealous envy ('iri') & Jealous \\
Cynical envy ('sirik') & No equivalence \\
Wanting to be different ('ghibtah') & No equivalence \\
Dislike or hate & Anger, hate, ill will \\
Cannot bare (to see it happen) & No equivalence \\
\hline
\end{tabular}

The Javanese word for malicious envy ('dengki') was divided into somewhat narrower categories in the Swedish coding, but it was the category most associated with envy in both countries. As mentioned earlier, the Swedish use of the word 'jealousy' is usually related to romantic relations. They can be mixed in the sense of being jealous if one's partner is romantically involved with in another person (emotional direction is the partner), and that person will become the envied one since he/she has the partner's attention (emotional direction is the third person). It cannot, however, be mixed with the word envy, as in the Indonesian categorisation. There were also similarities in the category of anger and hate. The Swedish coding referred the word 'ill will' to the 'dislike, hate' category, while the Indonesian coding refers 'ill will' to malicious envy. Nevertheless, the words were often associated with envy in both cultures. There was no equivalence to the Indonesian word 'cynical envy' in the Swedish data, or 'wanting to be different'. The latter maybe depends on the religious difference of 'Ghibtah' (envy that is free from malice), that is, only a wish to have the desired object but without the removal of the blessing from others. This is a clear distinction between the two countries. The view from the Europe/American studies is that envy, in its deeper meaning, cannot be free from malice, but probably differ considerably in intensity. The last category 'cannot bear' is not among the Swedish associative words.

Situations of being envious towards someone - It was possible to use the same categories in the two coding schemas on seven categories, see Table 11.

There were large differences in the two cultures regarding the causes of envy. The Swedish respondents were much more envious with respect to Materialistic aspects than the Javanese respondents were. There is no reason to believe that poverty has anything to do with the difference since the Javanese respondents were students on University level and can be assumed economically well off. Speculatively, maybe it is a matter of sharing in an extended family, that is, Indonesian families share more of their belongings and prosperity than the Swedish families. The Javanese group showed more envy on aspects as 'personal development' and 'academic achievements' than the Swedish group, while Swedish respondents more often mentioned the family aspect. The 
Adrianson, L. \& Ramdhani, N.

former can be due to having a high status in the Indonesian society and the use of different 'rankings' (more comparable with the British/American system of ranking between students) than in Sweden. The latter can be due to differences in family constellation that is more determined and outspoken in a collectivistic culture than in an individualistic. A young child is not envious if an older sibling is getting more of something; it is expected to be that way. The smallest differences were in the categories of 'social relations' and 'physical attraction' that also Rodriguez Mosquera et al. (2010) found.

\section{Table 11}

Aspects of Envy, Countries, Percentage

\begin{tabular}{lcc}
\hline \multicolumn{1}{c}{ Category } & Swedish respondents \% & Javanese respondents \% \\
\hline General and is 'something' & 16 & 25 \\
Personal development & 5 & 24 \\
Academic achievements & 4 & 16 \\
Social relations & 12 & 11 \\
Family & 16 & 5 \\
Materialistic aspects & 18 & 5 \\
Physical attraction & 3 & 5 \\
\hline
\end{tabular}

Situations when envied by other people - We could also compare the categories of situations when the respondents were subjected to envy, see Table 12. The Swedish responses of 'love' are included in the category 'Social relation', while the Indonesian coding had a separate category for 'love'. To increase the possibilities for comparisons we included 'love' into 'Social relations' also in the Indonesian categorisation.

\section{Table 12}

Aspects of Being Envied, Countries, Percentage

\begin{tabular}{lcc}
\hline \multicolumn{1}{c}{ Category } & Swedish respondents \% & Javanese respondents \% \\
\hline Personal development & 7 & 29 \\
Academic achievements & 6 & 19 \\
Social relations & 12 & 22 \\
General and is 'something' & 15 & 13 \\
Materialistic aspects & 10 & 7 \\
Family & 8 & 5 \\
Physical attraction & 4 & 2 \\
\hline
\end{tabular}

As can be seen in Table 12 the main differences are, again, in the categories of Personal development and Academic achievements, respectively. The Javanese respondents had felt envy from other persons in those aspects to a much higher degree than the Swedish respondents had. The other categories show similar results. It seems as the Javanese respondents compared themselves, and were compared, upwards while the Swedish respondents did their comparison among their likes.

\section{General Discussion}

The current study has described the experience of envy in two cultures. The comparisons between cultures are superficial depending on the way we collected and analysed data. Culture provides the overall framework wherein humans learn to organise their thoughts, emotions, and behaviours in relation to their environment. Although people are born into a culture, it is not innate; culture is learned (Alberoni, 1993; Kast, 2002; Quintanilla, 2013). Culture teaches one how to think, conditions one how to feel, and instructions on how to act, especially how to interact with others. People from different cultures learn different implicit theories on socialisation (Bandura, 1963) and through these individuals also learn the dominant values of their particular culture and their self-identities. There can be a striving for approval from the within group and not stand out but by conforming to the group's norm, or there can be a quest to be unique and show independence. The cultural characteristics, development and functions of psychological phenomena are shaped by social activities and cultural concepts. 
Most cultures have a word meaning envy, even though words for other common social phenomena may be absent. Although envy is an emotion, found in most cultures and felt by most people, there are important individual differences in the inclination to feel it. Envy is a more complex concept in Bahasa Indonesia than it is in the Swedish language and there were several words with an emotional content that was difficult to match in this study. Jealousy and envy overlap each other more in the Indonesian use of language than in the Swedish and the latter also has a distinct word for schadenfreude that is lacking in Bahasa Indonesia. Benign envy is not common in Swedish and when it is, the meaning is different from Ghibtah. Even though both malicious and benign envy can be experienced as painful and frustrating, give rise to inferiority, and cause people to be ashamed of their thoughts, they involve different motivations, according to Van de Ven et al. (2009). Whereas malicious envy is primarily associated with a motivation to tear others down, benign envy is for the most part associated with a motivation to build oneself up. The latter was shown in the Javanese's' responses more often than in the Swedish group.

Regardless of the lexical differences, there were similarities between the Swedish and Javanese respondents' experiences of envy. The proportionally large collection of 'something' in both cultures showed the complexity of the emotion. It can be an expression of being uncomfortable with both the self and the situation but also the society's disapproval of envious behaviour. In a comparison, the individual has to appraise themselves and when the shortcomings are obvious envy can occur. It is more likely when the desired object, talent or position is within reach and the question 'Why not me?' can be asked. It thus seems evident that 'wanting to have what another person possesses' can be a central element of envy as Crusius and Mussweiler (2011) suggested. This 'possession' can be envy on prosperity, on a high status position in the society, or envy on personal developments. It could also be interpreted as Smith et al.'s concept on dispositional envy, an on-going comparison with other people who always seems to get the better end of the stick. Parrot (1991) and Smith and Kim (2007) listed 'relationships, achievements and personal characteristics' as main causes for envy which was in line with the Indonesian results more than the Swedish. The similarity between being envious of something and be envied for something can be explained by the consensus within the culture. The more an individual cares about something, the more he/she believe that their own achievements would cause other persons in the same culture to desire what they have (Rodriguez Mosquera et al., 2010). Both the Swedish and Javanese respondents reported being envied by a person who they knew and with whom they had an established relationship, such as a friend or a fellow student and similar results were reported by among European Americans and Spanish respondents in Rodriguez Mosquera et al's.' study.

The Swedish respondents' descriptions were almost without exceptions with a malicious (ill will) meaning while it was obvious that the Javanese used also the concept of benign envy (without ill will). In the Spanish culture they often added the word 'healthy' to the word 'envy' (Rodriguez Mosquera et al., 2010) and maybe this can have some likeness to the Javanese benign words that resulted in responses of motivation, appreciation, creation of relations, and even asking for advice.

In conclusion, the present study contributes to the understanding of the emotion of envy. We could show that envy is a mixed feeling that is not so easy to verbalise, as expressed in the use of the vague, uncomfortable feeling of 'something' in both culture groups when asked to give reasons for being envious. We could also confirm and validate others' findings that it is a close friend, colleague or family member that we envy, and that also are envious of us. To feel inferior and 'to have what others have' was a more prominent reason to envy in the western culture while others' 'achievements' were envied in the East. This result is opposed to theories saying that vertical individualistic subjects are most concerned about achievement. A speculative explanation for this result can be that there are changes within cultures today and, maybe, the within-culture differences are increasing while the between-culture differences are decreasing, as our data is implicating. An interesting difference that we found between the cultures is the malicious envy in Western culture, relatively, and benign envy in the Eastern culture. The religion in both cultures condemns the emotion and it is not acceptable to show obvious envy among people. To use benign envy can be a way out for the collectivistic thinking group. Since we compare ourselves with our likes, they can use benign envy toward a person as a motivator, or role model and 
still show an acceptable feeling. It is much more of a quest to stand out as an individual in western cultures, although it gives rise to the displeasure of others as in the rules of Jante.

The weakness in this descriptive study is the lack of data to use for a more detailed comparison between the cultures, resulting in a low reliability. The principles of the coding did not always match and the respondents were heterogeneous in one culture (Sweden) and homogenous in the other. The purpose, however, was not to compare the cultures but to investigate if there were associative words for envy within the two cultures and if the reason for envious feelings were similar. The question whether envy is a universal emotion, or learned by socialisation and language is unanswered, to our knowledge, and needs further exploration in the research of human emotion.

\section{References:}

Alberoni, F. (1993). Envy. England: Cox \& Wyman Ltd.

Aristotle. (350 B.C.E). The Rhetoric. (Translation W. Rhys Roberts). Retrieved January 10, 2014, from http://classics.mit.edu/Aristotle/rhetoric.html

Aziz, S. A. (2006). Jealousy and its cures. As-Sunnah Bi-Monthly Newsletter, 19. Retrieved January 29, 2014, from www.ahya.org

Bandura, A. (1963). Social learning and personality development. New York: Holt, Rinehart, and Winston.

Breugelmans, S. M., \& Poortinga, Y. H. (2006). Emotion without a word: Shame and guilt among Rara'muri Indians and rural Javanese. Journal of Personality and Social Psychology, 91(6), 1111-1122. http://dx.doi.org/10.1037/0022-3514.91.6.1111

Brigham, N. L., Kelso, K. A., Jackson, M. A., \& Smith, R. H. (1997). The roles of invidious comparisons and deservingness in sympathy and Schadenfreude. Basic and Applied Social Psychology, 19, 363-380. http://dx.doi.org/10.1207/s15324834basp1903_6

Callaghan, T., Rochat, P., Lillard, A., Claux, M. L., Odden, H., Itakura, S., Tapanya, S., \& Singh, S. (2007). Synchrony in the onset of mental-state reasoning. Psychological Science, 5, 378-384.

Chang, H.-C. (1997). Language and words: Communication in the analects of on Confucius. Journal of Language and Social Psychology, 16(2), 107-131. http://dx.doi.org/10.1177/0261927X970162001

Cohen-Charash, Y. (2009). Episodic envy. Journal of Applied Social Psychology, 39(9), 2128-2173. http://dx.doi.org/10.1111/j.1559-1816.2009.00519.x

Cohen-Charash, Y., \& Mueller, J. S. (2007). Does perceived unfairness exacerbate or mitigate interpersonal counterproductive work behaviours related to envy? Journal of Applied Psychology, 92(3), 666-680. http://dx.doi.org/10.1037/0021-9010.92.3.666

Crosby, F. (1976). A model of egoistical relative deprivation. Psychological Review, 83, 85-113. http://dx.doi.org/10.1037/0033-295X.83.2.85

Crusius, J., \& Mussweiler, T. (2011, May 23). When people want what others have: The impulsive side of envious desire. Emotion. Advance online publication.

Dante, A. (1802). The divine comedy, Hell and purgatory (Translation Henry Boyd). Digital by Google 2007, http://books.google.se/books

Dogan, K., \& Veccio, R. P. (2001). Managing envy and jealousy in the workplace. Compensation Benefits Review, 33, 57-64. http://dx.doi.org/10.1177/08863680122098298

Duffy, M. K., \& Shaw, J. D. (2000). The Salieri syndrome: Consequences of envy in groups. Small Group Research, 31(3), 3-23. http://dx.doi.org/10.1177/104649640003100101

Epstein, J. (2003). The green-eyed monster. Washington Post, July/August. Retrieved February 7, 2014, from http://www.washingtonmonthly.com/features/2003/0307.epstein.html

Feather, N. T. (1994). Attitudes toward high achievers and reactions to their fall. In M. P. Zanna (Ed.), Advances in experimental social psychology (26, pp. 1-73). San Diego, CA:Academic Press.

Feather, N. T. (2012). Tall poppies, deservingness, and schadenfreude. The Psychologist, 6, 434-437.

Feather, N. T., \& Nairn, K. (2005). Resentment, envy, schadenfreude, and sympathy: Effects of own another's 
Why you and not me? Expressions of envy in Sweden and Indonesia

deserved or undeserved status. Australian Journal of Psychology, 57(2), 87- 102. http://dx.doi.org/10.1080/00049530500048672

Feather, N. T., \& Sherman, R. (2002). Envy, resentment, schadenfreude, and sympathy: Reactions to deserved and undeserved achievement and subsequent failure. Personality and Social Psychology Bulletin, 28(7), 953-961. http://dx.doi.org/10.1177/014616720202800708

Feather, N. T., McKee, I. R., \& Bekker, N. (2011). Deservingness and emotions: Testing a structural model that relates discrete emotions to the perceived deservingness of positive or negative outcomes. Motivation and Emotion, 35(1), 1-13. http://dx.doi.org/10.1007/s11031-011-9202-4

Feather, N. T., Wenzel, M., \& McKee, I. R. (2013). Integrating multiple perspectives on schadenfreude: The role of deservingness and emotions. Motivation and Emotion, 37, 574-585.

http://dx.doi.org/10.1007/s11031-012-9331-4

Festinger, L. (1954). A theory of social comparison processes. Human Relations, 7, 117-140. http://dx.doi.org/10.1177/001872675400700202

Fischer, P., Kastenmüller, A., Frey, D., \& Peus, C. (2009). Social comparison and information transmission in the work context. Journal of Applied Social Psychology, 39(1), 42-61. http://dx.doi.org/10.1111/j.1559-1816.2008.00428.x

Fontaine, R. J., Poortinga, Y. H., Setiadi, B., \& Markham, S. S. (2002). Cognitive structure of emotion terms in Indonesia and the Netherlands. Cognition and Emotion, 16(1), 61-86. http://dx.doi.org/10.1080/02699933014000130

Foster, G. (1972). The anatomy of envy: A study in symbolic behaviour. Current Anthropology, 13, $165-202$. http://dx.doi.org/10.1086/201267

Gino, F., \& Pierce, L. (2009). The abundance effect: Unethical behavior in the presence of wealth. Organizational Behavior and Human Decision Processes, 109, 142-155. http://dx.doi.org/10.1016/j.obhdp.2009.03.003

Grow, G. O. (1996). Don't hate me because I'm beautiful: A commercial in context. Retrieved January 10, 2014 , from http://www.longleaf.net/ggrow.

Hareli, S., \& Weiner, B. (2002). Dislike and envy as antecedents of pleasure at another's misfortune. Motivation and Emotion, 26(4), 257-277. http://dx.doi.org/10.1023/A:1022818803399

Haslam, N., \& Bornstein, B. H. (1996). Envy and jealousy as discrete emotions: A taxometric analysis. Motivation and Emotion, 20(3), 255-272. http://dx.doi.org/10.1007/BF02251889

Hill, S. E., \& Buss, D. M. (2008). The evolutionary psychology of envy. In R. H. Smith (Ed.), Envy: Theory and research (pp. 60-70). New York: Oxford University Press. http://dx.doi.org/10.1093/acprof:oso/9780195327953.003.0004

Hill, S. E., DelPriore, D. J., \& Vaughan, P. W. (2011, May 30). The cognitive consequences of envy: Attention, memory, and self-regulatory depletion. Journal of Personality and Social Psychology. Advance online publication.

Hogg, M., Abrams, D., Otten, S., \& Hinkle, S. (2004). The social identity perspective: Inter-group relations, self-conception, and small groups. Small Group Research, 35(3), 246-276. http://dx.doi.org/10.1177/1046496404263424

Hupka, R. B., Lenton, A. P., \& Hutchison, K. A. (1999). Universal development of emotion categories in natural language. Journal of Personality and Social Psychology, 77(2), 247-278. http://dx.doi.org/10.1037/0022-3514.77.2.247

Hupka, R. B., Otto, J., Tarabrina, N. V., \& Reidl, L. (1993). Cross-cultural comparisons of nouns associated with jealousy and the related emotions of envy, anger, and fear. Cross-Cultural Research, 27(3-4), 181-211. http://dx.doi.org/10.1177/106939719302700302

Kast, V. (2002). Envy and Jealousy. [In Swedish]. Stockholm: Natur \& Kultur.

Kim, H-J. J., \& Hupka, R. B. (2002). Comparison of associative meaning of concepts of anger, envy, fear, romantic jealousy, and sadness between English and Korean. Cross-Cultural Research, 36(3), 229-255. http://dx.doi.org/10.1177/10697102036003003

Klein, M. (2003). Envy and gratitude: A study of unconscious sources. Taylor \& Frances, Rutledge. 
Adrianson, L. \& Ramdhani, N.

Korvela, N. (2008). Work performance and wages: Distributive justice and emotional reactions. (Report Nr. 1101-718X). Gothenburg: Department of Psychology Reports.

Leach, C. W., \& Spears, R. (2008). "A vengefulness of the impotent": The pain of in-group inferiority and schadenfreude toward successful out-groups. Journal of Personality and Social Psychology, 95, 1383-1396. http://dx.doi.org/10.1037/a0012629

Maijala, H., Munnukka, T., \& Nikkonen, M. (2000). Feeling of "lacking” as the core of envy: A conceptual analysis of envy. Journal of Advanced Nursing, 31(6), 1342-1350. http://dx.doi.org/10.1046/j.1365-2648.2000.01428.x

Martin, B. (1996). Status and envy in academia. Campus Review, 23-29, p.9.

Massé, L., \& Gagné, F. (2002). Gifts and talents as sources of envy in high-school settings. Gifted Child Quarterly, 46(1), 15-29. http://dx.doi.org/10.1177/001698620204600103

Miceli, M., \& Castelfranchi, C. (2007). The envious mind. Cognition and Emotion, 21, 3, 449-479. http://dx.doi.org/10.1080/02699930600814735

Norman, R. (2002). Equality, envy, and the sense of injustice. Journal of Applied Philosophy, 19(1), 43-54. http://dx.doi.org/10.1111/1468-5930.00203

Nosanchuk, T. A., \& Erikson, B. H. (1985). How high is up? Calibrating social comparison in the real world. Journal of Personality and Social Psychology, 48(3), 624-634. http://dx.doi.org/10.1037/0022-3514.48.3.624

Oyserman, D., Coon, H. M., \& Kemmelmeier, M. (2002). Rethinking individualism and collectivism: Evaluation of theoretical assumptions and meta-analyses. Psychological Bulletin, 128(1), 3-72. http://dx.doi.org/10.1037/0033-2909.128.1.3

Parrott, W. G., \& Smith, R. H. (1993). Distinguishing the experiences of envy and jealousy. Journal of Personality and Social Psychology, 64(6), 906-920. http://dx.doi.org/10.1037/0022-3514.64.6.906

Patient, D., Lawrence, T., B., \& Maitlis, S. (2003).Understanding workplace envy through narrative fiction. Organization Studies, 24(7), 1014-1024. http://dx.doi.org/10.1177/01708406030247002

Quintanilla, L., \& Jensen de Lo'pez, K. (2013). The niche of envy: Conceptualization, coping strategies, and the ontogenesis of envy in cultural psychology. Culture \& Psychology, 19(1), 76-94. http://dx.doi.org/10.1177/1354067X12464980

Ratner, C. (2000). A cultural-psychological analysis of emotions. Culture \& Psychology, 6(1), 5-39. http://dx.doi.org/10.1177/1354067X0061001

Rodriguez Mosquera, P.M., Parrot, W.G., \& Hurtado de Mendoza, A. (2010). I fear your envy, I rejoice in your coveting: on the ambivalent experience of being envied by others. Journal of Personality and Social Psychology, 99(5), 842-854. http://dx.doi.org/10.1037/a0020965

Sabini, J., \& Silver, M. (2005). Why emotion names and experiences don't neatly pair. Psychological Inquiry, 16, 1-10. http://dx.doi.org/10.1207/s15327965pli1601_01

Salovey, P., \& Rodin, J. (1984). Some antecedents and consequences of social-comparison jealousy. Journal of Personality and Social Psychology, 47(4), 780-792. http://dx.doi.org/10.1037/0022-3514.47.4.780

Sandemose, A. (1933/1936). A fugitive crosses his tracks (Eugene Gay-Tifft. New York.).

Schnall, S., Roper, J., \& Fessler, D. M. (2010). Elevation leads to altruistic behaviour. Psychological Science, 21(3), 315-320. http://dx.doi.org/10.1177/0956797609359882

Schoeck, H. (1969). Envy: A theory of social behaviour. New York: Harcourt, Brace and World.

Schriffrin, R. M., \& Schneider, W. (1977). Controlled and automatic human information processing: II. Perceptual learning, automatic attending, and general theory. Psychological Review, 84, 127-190. http://dx.doi.org/10.1037/0033-295X.84.2.127

Smith, R. H. (2008). Envy: Theory and research. (Ed.) Oxford, UK: Oxford University Press. http://dx.doi.org/10.1093/acprof:oso/9780195327953.001.0001

Smith, R. H., \& Kim, S. H. (2007). Comprehending envy. Psychological Bulletin, 133(1), 46-64. http://dx.doi.org/10.1037/0033-2909.133.1.46

Smith, R. H., Kim, S. H., \& Parrott, W. G. (1988). Envy and jealousy: Semantic problems and experiential distinctions. Personality and Social Psychology Bulletin, 14, 401-409. 
Why you and not me? Expressions of envy in Sweden and Indonesia

http://dx.doi.org/10.1177/0146167288142017

Smith, R. H., Parrott, W. G, Diener, E., Hoyle, R. H., \& Kim, S. H. (1999). Dispositional envy. Personality and Social Psychology Bulletin, 25, 1007-1020. http://dx.doi.org/10.1177/01461672992511008

Smith, R. H., Turner, T., Garonzik, R., Leach, C., Urch-Druskat, V., \& Weston, C. M. (1996). Envy and schadenfreude. Personality and Social Psychology Bulletin, 22, 158-168. http://dx.doi.org/10.1177/0146167296222005

Spielman, P. M. (1971). Envy and jealousy: An attempt at clarification. Psychoanalytic Quarterly, 40, 59-82.

Tai, K.,Narayanan, J., \& McAllister, D. J. (2012). Envy as pain: Rethinking the nature of envy and its implications for employees and organizations. Academy of Management Review, 37(1), 107-129.

Tellenbach, H. (1974). On the nature of jealousy. Journal of Phenomenological Psychology, 4, 461-468. http://dx.doi.org/10.1163/156916274X00072

Triandis, H. C., \& Gelfand, M. J. (1998). Converging measurement of horizontal and vertical individualism and collectivism. Journal of Personality and Social Psychology, 74(1), 118-128. http://dx.doi.org/10.1037/0022-3514.74.1.118

Tyler, T. R. (1989). The psychology of procedural justice: A test of the group-value model. Journal of Personality and Social Psychology, 57(5), 830-838. http://dx.doi.org/10.1037/0022-3514.57.5.830

Van de Ven, N., Zeelenberg, M., \& Pieters, R. (2009). Leveling up and down: The experiences of benign and malicious envy. Emotion, 9(3), 419-429. http://dx.doi.org/10.1037/a0015669

Van de Ven, N., Zeelenberg, M., \& Pieters, R. (2010). Warding off the evil eye: When the fear of being envied increases prosocial behavior. Psychological Science, 21(11), 1671-1677. http://dx.doi.org/10.1177/0956797610385352

Van de Ven, N., Zeelenberg, M., \& Pieters, R. (2011). Why envy outperforms admiration. Personality and Social Psychology Bulletin, 37(6), 784-795. http://dx.doi.org/10.1177/0146167211400421

Van de Ven, N., Zeelenberg, M., \& Pieters, R. (2012). Appraisal patterns of envy and related emotions. Motivation and Emotion, 36, 195-204. http://dx.doi.org/10.1007/s11031-011-9235-8

van Dijk, W. W., Ouwerkerk, J. W., Goslinga, S., Nieweg. M., \& Gallucci, M. (2006). When people fall from grace: Reconsidering the role of envy in schadenfreude. Emotion, 6 (1), 156-160.

http://dx.doi.org/10.1037/1528-3542.6.1.156

van Dijk, W. W., Ouwerkerk, J. W., Wesseling, Y. M., \& van Konigsbruggen, G. M. (2011). Towards understanding pleasure at the misfortunes of others: The impact of self-evaluation threat on schadenfreude. Cognition and Emotion, 25(2), 360-368. http://dx.doi.org/10.1080/02699931.2010.487365

Vecchio, R. P. (2005). Explorations in employee envy: Feeling envious and feeling envied. Cognition and Emotion, 19(1), 69-81. http://dx.doi.org/10.1080/02699930441000148

Wert, S., R., \& Salovey, P. (2004). A social comparison account of gossip. Review of General Psychology, 8(2), 122-137. http://dx.doi.org/10.1037/1089-2680.8.2.122

Weyl, N. (1984). Envy and aristocide. The Eugenics Bulletin, Winter.

Wigley, S. (2000, April). Impartiality and envy. Paper presented at the Political Studies Association 50th Annual Conference, London, U.K.

Williams, T. (2003). Moral vice, cognitive virtue: Austen on jealousy and envy. Philosophy and Literature, 27, 223-230. http://dx.doi.org/10.1353/phl.2003.0033 
Adrianson, L. \& Ramdhani, N. 